\title{
LETTER
}

\section{Renal function and thromboprophylaxis in critically ill patients}

\author{
Gareth M Scholey, Anton G Saayman, Christopher D Hingston and Matt P Wise \\ See related research by Robinson et al., http://ccforum.com/content/14/2/R41
}

Robinson and colleagues [1] recently examined the effective dose of enoxaparin for thromboprophylaxis in critically ill patients recorded over 24 hours. The study concluded that the standard dose of $40 \mathrm{mg}$ led to subtherapeutic anti-factor Xa activity (aFXa) and $60 \mathrm{mg}$ daily was optimal. The high rate of thromboembolic disease observed in critically ill patients could thus be explained by inadequate aFXa with the standard $40 \mathrm{mg}$ dose.

Low molecular weight heparins (LMWHs) are renally excreted and Robinson and colleagues excluded patients receiving renal replacement therapy as this may have influenced aFXa [1]. Douketis and colleagues [2] documented that excessive anticoagulation did not occur with prophylactic doses of dalteparin in critically ill patients with severe renal impairment. However, in a study of two different prophylactic LMWHs in elderly patients with impaired renal function, enoxaparin but not tinzaparin accumulated over 8 days [3]. The pharmacokinetics of different LMWHs varies [3,4], and excessive anticoagulation over time might occur with a $60 \mathrm{mg}$ daily dose of enoxaparin, especially if renal function is impaired.

Perturbations of renal function may also explain why standard dose enoxaparin is subtherapeutic in many critically ill patients [1]. Fuster-Lluch and colleagues [5] reported that $30 \%$ of patients show augmented renal clearance during the first week of critical illness. Typically, those with supranormal creatinine clearance were postoperative patients or had sepsis or trauma. This patient group is hypercoagulable and at high risk of thromboembolic disease; however, augmented renal clearance would reduce the effectiveness of LMWHs. The optimal prophylactic dose of $\mathrm{LMWHs}$ in critical illness is probably, therefore, best determined by monitoring of aFXa.

\section{Authors' response}

Sian Robinson, Palle Toft and Thomas Strøm

We thank Dr Scholey and colleagues for the careful reading of our paper, and agree that the problem of prophylactic anticoagulation in this patient population is a complex one. Whilst our study seems to support the theory of inadequate dosage being a possible mechanism for the higher failure rate of enoxaparin in ICU patients, we acknowledge that there may be other possible mechanisms at play. Scholey and colleagues point to augmented renal function in particular, while still other researchers have implicated the presence of multiple organ dysfunction syndrome, obesity, and the use of vasopressors as likely culprits [6].

*Correspondence: mattwise@doctors.org.uk

Adult Critical Care, University Hospital of Wales, Cardiff, UK
Conversely, Dr Scholey and colleagues note that renal impairment may lead to the bioaccumulation of a $60 \mathrm{mg}$ dose of enoxaparin. In fact, renal impairment may lead to enoxaparin accumulation at standard doses [7], and most authorities advocate avoidance of LMWHs in this patient population [8]. Such patients were thus excluded from our study. However, patients with renal impairment do account for a sizeable portion of ICU clientele, and it is incongruous to attempt the establishment of guidelines for the use of LMWH prophylaxis in ICU patients, whilst continuing to exclude this important subgroup.

aFXa is only a surrogate parameter, one that has never been conclusively shown to be directly related to clinical outcome $[9,10]$. We are currently at the design phase in a study intended to determine whether the improved aFXa levels associated with $60 \mathrm{mg}$ enoxaparin will translate into fewer venous thromboembolic events without the concomitant risk of increased bleeding episodes. 


\section{Abbreviations}

$\mathrm{aFXa}=$ anti-factor $\mathrm{Xa}$ activity; LMWH = low molecular weight heparin.

\section{Competing interests}

The authors declare that they have no competing interests.

Published: 12 May 2010

\section{References}

1. Robinson S, Zincuk A, Strom T, Larsen TB, Rasmussen B, Toft P: Enoxaparin effective dosage for intensive care patients: double blinded randomised control trial. Crit Care 2010, 14:R41.

2. Douketis J, Cook D, Meade M, Guyatt G, Geerts W, Skrobik Y, Albert M, Granton J, Hebert P, Pagliarello G, Marshall J, Fowler R, Freitag A, Rabbat C, Anderson D, Zytaruk N, Heels-Ansdell D, Crowther M; Canadian critical care trials group: Prophylaxis against deep vein thrombosis in critically ill patients with severe renal insufficiency with low molecular weight heparin dalteparin; An assessment of safety and pharmacodynamics: The DIRECT study. Arch Intern Med 2008, 168:1805-1812.

3. Mahe I, Aghassarian M, Drouet L, Bal Dit-Sollier C, Lacut K, Heilmann JJ, Mottier D, Bergmann JF: Tinzaparin and enoxaparin given at prophylactic dose for eight days in medical elderly patients with impaired renal function: a comparative pharmacokinetic study. Thromb Haemost 2007, 97:581-586.

4. Samama MM, Gerotziafas GT: Comparative pharmacokinetics of LMWHs. Semin Thromb Hemost 2000, 26 Suppl 1:31-38.

5. Fuster-Lluch O, Geronimo-Pardo M, Peyro-Garcia R, Lizan-Garcia M:
Glomerular hyperfiltration and albuminuria in critically ill patients. Anaesth Intensive Care 2008, 36:674-680.

6. Mayr AJ, Dünser M, Jochberger S, Fries D, Klingler A, Joannidis M, Hasibeder W, Schobersberger W: Antifactor Xa activity in intensive care patients receiving thromboembolic prophylaxis with standard doses of enoxaparin. Thromb Res 2002, 105:201-204.

7. Lim W, Dentali F, Eikelboom JW, Crowther MA: Meta-analysis: low-molecularweight heparin and bleeding in patients with severe renal insufficiency. Ann Intern Med 2006, 144:673-684

8. Geerts WH, Bergqvist D, Pineo GF, Heit JA, Samama CM, Lassen MR, Colwell CW; American College of Chest Physicians: Prevention of venous thromboembolism: American College of Chest Physicians Evidence-Based Clinical Practice Guidelines (8th Edition). Chest 2008, 133: 381S-453S

9. Bara L, Planes A, Samama MM: Occurrence of thrombosis and haemorrhage, relationship with anti-Xa, anti-Ila activities, and D-dimer plasma levels in patients receiving a low molecular weight heparin, enoxaparin or tinzaparin, to prevent deep vein thrombosis after hip surgery. Br J Haematol 1999, 104:230-240.

10. Brophy DF, Carr ME Jr, Martin EJ, Venitz J, Gehr TW: The pharmacokinetics of enoxaparin do not correlate with its pharmacodynamic effect in patients receiving dialysis therapies. J Clin Pharmacol 2006, 46:887-894.

doi:10.1186/cc8985

Cite this article as: Scholey GM, et al:: Renal function and

thromboprophylaxis in critically ill patients. Critical Care 2010, 14:416. 